\title{
Emergency severity index version 4 during the first year of implementation at an academic institution
}

\author{
Preeti Dalawari ${ }^{* 1}$, Jacob Sanning ${ }^{1}$, Dana Pan $^{1}$, Jennifer Storm ${ }^{2}$ \\ ${ }^{1}$ Division of Emergency Medicine, Saint Louis University School of Medicine, Saint Louis, Missouri, United States \\ ${ }^{2}$ Doisy College of Health Sciences, Saint Louis University, Saint Louis, Missouri, United States
}

Received: October 8, 2015

Accepted: December 11, 2015

Online Published: December 22, 2015

DOI: $10.5430 /$ jha.v5n2p35

URL: http://dx.doi.org/10.5430/jha.v5n2p35

\begin{abstract}
Background: The Emergency Severity Index (ESI) version 4 (v4) is a triage system based on vital signs, potential limb or organ threat, as well as expected resources needed in the emergency department (ED).

Objective: The purpose of this study was to examine accuracy and misclassification rate of ESI triage over one year following implementation.

Methods: This was a retrospective analysis of ED encounters from January 2011 to 2012. Charts were selected in one-week intervals every 12 weeks for one year (months 1, 3, 6, 9, and 12). Each encounter was reviewed to determine post hoc ESI level based on care in the ED. Descriptive statistics was used to compare the agreement between initial triage and post hoc ESI levels. Sensitivity and specificity for each level was determined. Kruskal Wallis test (KW) and Mann Whitney U (MWU) was used to assess differences in initial versus post hoc ESI levels by month to explore change in accuracy over time.

Results: Five hundred and sixty separate ED encounters were included. Agreement was observed in 301 triage encounters $(53.8 \%)$. Overestimation of the triage level occurred in 131 (23.4\%) encounters, while the triage level was underestimated in 128 $(22.9 \%)$ encounters. There was a significant decline in accuracy during the year ( $\mathrm{KW}=10.2 ; p=.037)$; with the greatest drop between month 1 and 9 months (MWU 4,859; $p=.035$ ). Sensitivity ranged from $24 \%$ to $76 \%$ and specificity ranged from $61 \%$ to 99\%, based on ESI level.
\end{abstract}

Conclusions: Enhanced education and quality improvement process is necessary to improve overall accuracy rates at this site.

Key Words: Emergency severity index, Triage system, Emergency department

\section{INTRODUCTION}

Triage in the emergency department (ED) begins with an assessment allowing for the incoming patient volume to be prioritized into those who require immediate care and others with less acute needs. According to Centers for Disease Control (CDC) statistics, in 2010 there were 129.8 million visits to EDs and only $25.1 \%$ of these were seen in less than 15 minutes. ${ }^{[1]}$ Thus, proper triaging, especially with an influx of patient volume, is important for appropriate patient care, as failure could result in errantly leaving sick patients in the waiting room. A recent study by Yurkova suggests that under triage is a significant factor affecting transfer times between ED and intensive care unit, especially in septic patients. ${ }^{[2]}$

Further complicating the issue, ED overcrowding has emerged as a major barrier for timely triage. Between 1993 and 2003, the number of ED visits increased by $24 \%$ while

\footnotetext{
${ }^{*}$ Correspondence: Preeti Dalawari; Email: pdalawar@slu.edu; Address: School of Medicine Division of Emergency Medicine, 3635 Vista at Grand Avenue, First Floor Desloge Towers, Saint Louis, Missouri 63110, United States.
} 
the U.S. population increased $12 \%$. In the same time period, the total number of EDs in the country reduced by $425 .^{[3]}$ The effects of overcrowding in EDs has led to increased wait times and increased concerns that patient outcomes will suffer. ${ }^{[4-7]}$ One study found that during crowded conditions, patients with higher acuity such as chest pain or shortness of breath had longer wait times and were inappropriately roomed in non-monitored ED beds. In fact, overcrowding has been associated with increased patient mortality, delayed antibiotic administration, delayed resuscitation efforts, and poor pain management. ${ }^{[7]}$

In order to maintain quality care for ED patients, a joint committee of the Emergency Nurses Association (ENA) and the American College of Emergency Physicians (ACEP) encouraged the use of the Emergency Severity Index (ESI). ${ }^{[8]}$ It is the most widely used triage system in the United States and is becoming more widely used in other non English speaking countries. ${ }^{[9,10]}$ There are many other five level ED triage systems used worldwide including the Manchester Triage System (MTS), the Canadian Triage and Acuity Scale (CTAS), the Australasian Triage Scale (ATS), among other multi level informal systems. ${ }^{[5,11-13]}$ In both the ATS and CTAS system, each level has a time goal to initiation of medical evaluation. The CTAS uses a list of clinical descriptors and symptoms to assess triage level, as well repeating triage after a defined waiting period. ${ }^{[11,12,14]}$ The MTS has 52 presentational flow charts to assist in triage with six key discriminators (life threat, pain, hemorrhage, acuteness of onset, consciousness, and temperature). ${ }^{[11,12]}$

ESI is a standardized tool used to categorize patients based on acuity and estimated resource consumption. An ESI level 1 is considered emergent and an ESI 2 is considered urgent; requiring early provider evaluation and intervention to prevent significant morbidity and mortality. Those with ESI 3, 4 or 5 are less urgent and are stratified based on predicted resource utilization. The ESI system is endorsed by the Agency for Healthcare Research and Quality (AHRQ) and is currently in its 4th version, adapted from evidence-based research. ${ }^{[3,13]}$

The "ESI version 4 (v4): Implementation handbook" recommend training sessions involving instruction on the criteria that qualify for each ESI level as well as practice cases, such that nurses will leave the sessions proficient with the triage system. ${ }^{[3,13]}$ In the ED, however, the practical application of ESI can be a difficult task. To minimize errors in triage, it has been suggested that additional training is needed, at least in the geriatric and pediatric patient population. ${ }^{[15,16]}$ Many studies have shown that ESI and other triage systems are reliable (inter and intra observer variability) and valid (predicting "true" urgency). ${ }^{[5,12,17-19]}$ There is a dearth of information on optimal training for accuracy and need for retraining.

\section{Goal of this investigation}

The objective of this study was to determine if the implementation training was sufficient for triage nurses using accuracy and misclassification rate as the outcome, and if there was an optimal timeframe for retraining.

\section{MeThodS}

\subsection{Study design and setting}

This was a retrospective quality improvement analysis of a set of ED encounters between January 1, 2011 and January 1, 2012 at an academic level 1-trauma center with an ED annual volume of approximately 38,000. All nurses were trained in ESI v4 in the first week of January 2011 using the AHQR recommended training methods, including the implementation handbook and training DVD. ${ }^{[3]}$ The University's Institutional Review Board approved the study.

\subsection{Protocol and outcome measures}

Every $6^{\text {th }}$ chart for a one-week time frame at months 1 ( 2 weeks post implementation of the system) and every 12 weeks thereafter for one year were evaluated (months 3, 6, 9, and 12) by one of two research assistants (DP and JS). The chart review by the research assistants was done after the first year of ESI implementation was completed. In January 2012, the research assistants underwent the same ESI training session as the nurses with the AHQR training methods, prior to chart abstraction, by an experienced physician assistant who works at triage at our institution (JeS). A research assistant evaluated each encounter based on criteria defined by ESI v4.

ESI v4 was the only triage algorithm evaluated in this study. The "initial triage" ESI level given to the patient at the time of triage was collected from the electronic medical record. The research assistants determined an "actual" post hoc ESI level by reviewing the ED chief complaint, initial vital signs, lifesaving interventions, and actual resources utilized during the ED stay, as defined by the AHQR handbook. The lower the triage number, the higher the acuity of the patient. Misclassifications were defined as either under or over triages. Under triage was defined as assigning a lower acuity than the patient's actual acuity (i.e., assigning an ESI level 4 instead of an ESI level 1). Over triage assigned a higher acuity than necessary (triage ESI level lower than post hoc ESI level; assigning a 3 instead of 5). Ten percent of reviewed charts ("actual" post hoc ESI level) were subsequently randomly selected and reviewed for accuracy by JeS with a kappa value 
of 0.738

\subsection{Data analysis}

All data was analyzed using the Statistical Package for Social Sciences (SPSS) 19.0. Those leaving without being seen, without being triaged, or against medical advice were excluded from analysis due to difficulty in measuring resources used. Descriptive statistics was used to compare the agreement between initial triage and post hoc ESI levels. Sensitivity, the ability of triage nurse to correctly assign patients to the appropriate ESI designation and specificity, the ability to correctly not assign to an ESI level, were measured. Positive predictive value and negative predictive value were also calculated. For example, if the patient should be assigned level 1, sensitivity would be how often the nurse assigned level 1 . If the patient should not be assigned level 1 , specificity would be how often the nurse did not assign level 1. Kruskal Wallis test (KW) and Mann Whitney U (MWU) was used to assess differences in initial versus post hoc ESI levels by month to explore change in accuracy over time. Nurse accuracy level was also explored for those who did more than 20 triage encounters. Chi square analysis was used for differences in disposition groups by accuracy level.

\section{Results}

Six hundred and seven separate ED encounters were reviewed; 47 encounters were excluded due to difficulty calculating resource utilization in those leaving without being seen, without being triaged, or against medical advice. There were a total of 68 nurses who triaged at least one person in this timeframe (range 1-29 separate triage encounters).

Notable differences in initial and post hoc ESI are noted in Table 1.

As seen in Figure 1, agreement was observed in 301 triage encounters $(53.8 \%)$. Overestimation of the triage level occurred in $131(23.4 \%)$ encounters, while the triage level was underestimated in $128(22.9 \%)$ encounters.

Sensitivity and specificity for each level is listed in Table 2. Only $50.4 \%$ of discharged patients had agreement in ESI levels $(n=363)$ compared to $59.9 \%$ of admitted patients $(\mathrm{n}=197, p=.03)$.
There was a significant decline in accuracy during the year $(\mathrm{KW}=10.2 ; p=.037)$; with the greatest drop between month 1 and 9 months (MWU 4,859; $p=.035$ ) (see Table 3). Nurse level accuracy was explored and for those nurses who did more than 20 triage encounters in the sample (6 nurses, $\mathrm{N}=163$ encounters), the accuracy level was $56.3 \%$ (range $40 \%-73 \%$ ).

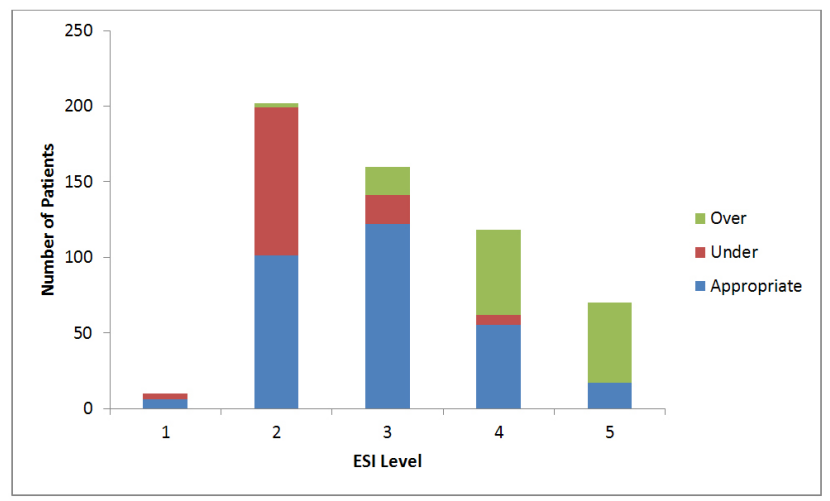

Figure 1. Over and under triages for each ESI level $(\mathrm{N}=560)$

\section{Discussion}

Triage nurses at this one institution accurately assigned triage level based on predicted resources and other criteria of the current ESI system, on average, only $53.8 \%$ of the time during the initial year of use. A Belgium hospital's implementation of ESI v4 revealed $78 \%$ accuracy with the highest misclassification occurring in ESI level 2, and under triages being more frequent than over triages. However, the accuracy level was measured by inter rater agreement of case scenarios which do not account for real time ED issues: staffing issues, nursing experience or training, nonverbal cues, or ED volumes that may contribute to misclassification of ESI levels. ${ }^{[20,21]}$ Farrohknia refers to this same issue when stating that study designs for inter rater agreement have been suboptimal, with many studies based on fictitious cases than real life settings. ${ }^{[2]}$ One of the initial validation studies using a retrospective design similar to our study and ESI v3, showed an $80 \%$ accuracy rate, but it was done ten months after the implementation of the system with an ongoing quality improvement process noting mis-triages. ${ }^{[18]}$

Table 1. Initial and post hoc (actual) ESI levels $(\mathrm{N}=560)$

\begin{tabular}{llllll}
\hline & ESI Level 1 N (\%) & ESI Level 2 N (\%) & ESI Level 3 N (\%) & ESI Level 4 N (\%) & ESI Level 5 N (\%) \\
\hline Initial ESI & $11(2.0)$ & $126(22.5)$ & $279(49.8)$ & $117(20.9)$ & $27(4.8)$ \\
Post Hoc ESI & $10(1.8)$ & $202(36.1)$ & $160(28.6)$ & $118(21.1)$ & $70(12.5)$ \\
\hline
\end{tabular}


Table 2. Sensitivity, specificity, negative and positive predictive values with $95 \%$ confidence intervals of ESI levels $(\mathrm{N}=560)$

\begin{tabular}{llll}
\hline & Sensitivity (95\% CI) & Specificity (95\% CI) & PPV (95\% CI) \\
\hline Level 1 & $60.0 \%(27.4,86.3)$ & $99.1 \%(97.8,99.7)$ & $54.5 \%(24.6,81.9)$ \\
Level 2 & $50.0 \%(42.9,57.1)$ & $93.0 \%(89.7,95.3)$ & $80.2 \%(71.9,86.5)$ \\
Level 3 & $76.3 \%(68.8,82.5)$ & $60.8 \%(55.8,65.5)$ & $43.7 \%(37.9,49.8)$ \\
Level 4 & $46.6 \%(37.4,56.0)$ & $86.0 \%(82.3,89.0)$ & $47.0 \%(37.8,56.4)$ \\
Level 5 & $24.3 \%(15.2,36.3)$ & $98.0 \%(96.1,99.0)$ & $63.0 \%(42.5,80.0)$ \\
\hline
\end{tabular}

Table 3. Accuracy level by month $(\mathrm{N}=560)$

\begin{tabular}{llll}
\hline Month & Total Triages & $\begin{array}{l}\text { Accurate Triages } \\
\text { N (\%) }\end{array}$ & $\begin{array}{l}\text { No. Nurses } \\
\text { Triaging }\end{array}$ \\
\hline 1 & 98 & $59(60.2)$ & 30 \\
3 & 104 & $65(62.5)$ & 31 \\
6 & 115 & $64(55.7)$ & 33 \\
9 & 116 & $53(45.7)$ & 38 \\
12 & 127 & $60(47.2)$ & 42 \\
\hline
\end{tabular}

There is a wide range of results regarding reliability (from fair to very good) and validity of triage systems in the literature; with ESI and CTAS having the highest reported reliability. ${ }^{[12,23,24]}$ However, a systematic review of different triage systems suggests there is limited and insufficient evidence for assessing validity and reliability in many triage scales, with variability in the methods and measurements (kappa, weighted kappa, Pearson). ${ }^{[22,23]}$ Validity is difficult to assess for triage acuity, as there is no true gold standard upon which to measure. ${ }^{[3]}$ Thus it is based on various proxy outcomes such as hospital admission, length of stay, and mortality. ${ }^{[5,12,14,17,25]}$ While ESI, MTS, and ATS are predictive of admission, Weber et al. noted that less than half of the high acuity patients completed triage within the ESI time frames. ${ }^{[12,26,27]}$

Our study, similar to Storm-Versloot et al., demonstrated that sensitivities for all levels were relatively poor (i.e. - ESI level 2 sensitivity $36 \%$; ESI level 3 sensitivity $50 \%$ ) with higher specificities for ESI levels 1 and 2, which may be due to the fact that lifesaving interventions and emergent therapies may be easier to distinguish than resource consumption. Using ESI v3, they found an under triage rate of $20 \%$ and an accuracy rate of less than $40 \% .{ }^{[5]}$ The ideal triage system will have a high sensitivity to identify those patients whose outcome is likely to worsen without intervention, and good specificity (there is always a trade off between specificity and sensitivity). ${ }^{[14]}$ Geriatric ESI literature shows similar sensitivities (in the mid-40s\%) and high specificities (99\%) for ESI level 1, and that this population is at risk of under triage ${ }^{[15,28]}$ Similarly, sensitivity and specificity in the MTS system for higher urgency levels in six studies ranged from $17 \%-63 \%$ and $78 \%-100 \% .^{[23]}$
Misclassification by use of higher ESI (under triaging) reflects a necessity for more extensive training for triage staff; as there will always be a trade off between safe practices overriding resource consumption. Among patients admitted to the ICU from the ED, one study shows a misclassification to a lesser acuity (for example, assigning an ESI 3 instead of an ESI 2), prolongs the wait in the ED. ${ }^{[2]}$ The difference in time may be critical; however, the impact of triage for many urgent conditions is unknown. ${ }^{[14]}$ In fact, one author suggests that correct assignment of acuity level does not guarantee better outcomes as those with higher acuity levels may have more risk factors for negative outcomes. ${ }^{[2,14]}$

Like previous studies, our study showed that nurses had difficulties with ESI level 2 (high acuity criteria) and predicted resource consumption..$^{[5,20]}$ Similarly, a study by Singer et al. ${ }^{[29]}$ surveying nurses found confusion in the distinction between ESI levels 2 and 3, while Garbez et al. stated research into this distinction is lacking. ${ }^{[30]}$ For example, the ESI handbook designated an ESI level 2 as a high-risk situation (a patient you would put in your last open bed), severe pain/distress, confused/lethargic/disoriented, or "danger zone" vitals. ${ }^{[3,13]}$ Garbez et al. argued that this may not be specific enough for less experienced nurses. ${ }^{[24,30]}$ Several studies showed that the ESI system has a tendency to allocate patients to ESI level 2. ${ }^{[19,24]}$ Singer et al. also noted that some respondents were misclassifying by using their perception of what tests the emergency physician may order or their own perception of the patient's condition, instead of using the exact ESI algorithm. ${ }^{[29]}$

While it is interesting to note that these nurse respondents thought the ESI triage system was helpful for less experienced nurses, the original intent is that this triage system is for experienced nurses. ${ }^{[3,29]}$ There are conflicting reports as to the amount of nursing experience needed for triage proficiency. Garbez cites studies that show that factual knowledge supersedes experiential knowledge when it comes to triage; however, experienced triage nurses are influenced by subjective individual and patient factors. ${ }^{[30,31]}$ The 2012 ESI Implementation handbook states that ESI is "intended for use by nurses with triage experience or those who have attended 
a separate, comprehensive triage educational program.,"[13] This highlights the difference in theoretical intent of ESI and the practical application in many EDs, as it may not always be possible to have the most experienced nurse at triage. Singer et al. also noted that few EDs have monitored the impact of ESI on variables such as predicting resource demand, ease of implementation, sorting patients clinically, or monitoring the accuracy of the triage levels as part of a quality improvement measure. ${ }^{[29]}$

In addition to subpar initial accuracy rates at this institution, there was a significant decline throughout the year with a nadir around month 9, possibly indicating a need to retrain at this time. Additional initial training may be necessary to increase accuracy rates. ${ }^{[3,29]}$ In addition to the live training and case scenarios, providing monthly summarizes of misclassifications as an educational tool would be beneficial, as was done in the Tanabe study. ${ }^{[18]}$ Other suggestions include obtaining training by a mentor, additional objective competency training, resource utilization training, continuing education, and monthly or at least quarterly feedback. ${ }^{[32]}$

It is important to note that it is not possible to completely eliminate over and under triages, and as such there is no standard of what is acceptable. Oftentimes, Cohen's Kappa values are used to measure inter and intra rater reliability, as it measures the agreement beyond chance between raters. ${ }^{[33]}$ There are many Kappa variations and some studies lack adequate description of the methods to ascertain which kappa was used. ${ }^{[22,23,33,34]}$ Because kappa values can not be directly interpreted, some authors suggest that researchers accept low values in their inter rater reliability studies, which may not be acceptable in health sciences or clinical studies. ${ }^{[33]}$ Many studies used weighted kappa values that may over estimate the reliability. ${ }^{[19,24]}$ For the six studies in the meta analysis on reliability of ESI, the overall agreement rate was $78.5 \%{ }^{[19]}$ We theorize that an acceptable level may be $70 \%$ agreement, especially since the ESI v4 training manual states that nurses using the ESI system were able to predict how may resources the ED patient required $70 \%$ of the time. ${ }^{[3,13]}$

\section{Limitations}

This study was limited by several factors. Restriction to a single institution limits the generalizability of the results. Furthermore, the current sample was only $1.5 \%$ of the total ED volume and a larger sample size of patients assigned ESI 1 would provide more insight to the most critical population to arrive at the ED. Another limitation of our triage process is the wide variability in nurses working from month to month, the amount each individual nurse triaged, the possible rotation of inexperienced nurses working in triage, as well as the fact that some patients likely were triaged in their room by their primary nurse who also may not be as experienced in triage (not a dedicated triage nurse). When nurses do not have a broad clinical experience background they may be less likely to recognize high-risk presentations or correctly interpret the ESI guidelines that could easily lead to under triaging patients. However, as indicated before, the practical application and the theoretical intent of ESI are not always the same depending on the hospital system and limitations. Using post hoc (retrospective) analysis of ESI is not the same as concurrent prospective agreement of ESI, whether by case scenarios, or in the ED. Triage is based on an initial assessment, yet patient conditions can change. ${ }^{[35]}$ Unlike CTAS where patient re-evaluation for triage level is codified, ESI will re-triage only as necessary. ${ }^{[11,24]}$ It can be argued that since triage is based on a presentation at a specific time, the whole ED visit should not be taken into account. ${ }^{[12]}$ However, when evaluating resource utilization for ESI levels, the ED course must be taken into account. All these factors can decrease the sensitivity and specificity of the ESI process. The research assistants were not blinded to the original ESI level as this could not be hidden in the electronic medical system. This may introduce some bias. The study was not designed to evaluate why misclassification of triage levels was occurring and future studies of specific populations, and patient, nursing, and systemic factors that contribute to this would be beneficial in aiding training efforts, as well as follow up studies to look for improvement in accuracy rate and proxy measures such as length of stay and mortality.

\section{Conclusions}

Accuracy rates for the initial year of implementation of ESI v4 at this hospital were suboptimal. There was a significant decline in accuracy throughout the year. Enhanced initial education is necessary to improve the overall accuracy rates and decrease misclassification, especially with ESI level 2. Decreasing nursing variability in triage, as well as a implementing a robust quality improvement initiative can further increase accuracy rates.

\section{ACKNOWLEDGEMENTS}

The authors would like to acknowledge Eric Armbrecht, PhD for assistance with statistics. 


\section{REFERENCES}

[1] National Hospital Ambulatory Medical Care Survey: 2010 Emergency Department Summary Tables. Available from: http://www.cdc.gov/nchs/data/ahcd/nhamcs_emergency/ 2010_ed_web_tables.pdf.Accessed09July2013

[2] Yurkova I, Wolf L. Under-triage as a significant factor affecting transfer time between the emergency department and the intensive care unit. J Emerg Nurs. 2011 Sep; 37(5): 491-6. PMid: 21549418. http://dx.doi.org/10.1016/j.jen.2011.01.016

[3] Gilboy N, Tanabe P, Travers D, et al. Emergency Severity Index, Version 4: Implementation Handbook. Agency for Healthcare Research and Quality (AHRQ) Publication. No. 05-0046-2. 2005.

[4] The Future of Emergency Care in the United States Health System. Consensus Report. Accessed June 5, 2013. Available from: http: //www.iom.edu/Activities/Quality/emergencycare.aspx

[5] Storm-Versloot MN, Ubbink DT, Kappelhof J, et al. Comparison of an informally structured triage system, the emergency severity index, and the manchester triage system to distinguish patient priority in the emergency department. Acad Emerg Med. 2011 Aug; 18(8): 822-9. PMid: 21843217. http://dx.doi .org/10.1111/j.1553-2712. 2011.01122.x

[6] Timm NL, Ho ML, Luria JW. Pediatric emergency department overcrowding and impact on patient flow outcomes. Acad Emerg Med. 2008 Sep; 15(9): 832-7. PMid: 18821860. http://dx.doi.org/1 $0.1111 / j .1553-2712.2008 .00224 . x$

[7] O'Connor E, Gatien M, Weir C, et al. Evaluating the effect of emergency department crowding on triage destination. Int J Emerg Med. 2014 Apr 28; 7: 16. PMid: 24860626. http://dx.doi.org/10. 1186/1865-1380-7-16

[8] American College of Emergency Physicians. ACEP policy statements: Triage scale standardization. 2010. Available from: http://www . acep.org/Content. aspx?id=29828\&ter $\mathrm{ms}=$ triage $\%$ scale

[9] McHugh M, Tanabe P, McClelland M, et al. More patients are triaged using the Emergency Severity Index than any other triage acuity system in the United States. Acad Emerg Med. 2012; 19(1): 106-9. PMid: 22211429. http://dx.doi.org/10.1111/j.1553-2712. 2011.01240.x

[10] Jordi K, Grossmann F, Gaddis GM, et al. Nurses' accuracy and self-perceived ability using the Emergency Severity Index triage tool: a cross-sectional study in four Swiss hospitals. Scand J Trauma Resusc Emerg Med. 2015; 23: 62. PMid: 26310569. http://dx.doi.org/10.1186/s13049-015-0142-y

[11] Christ M, Grossmann F, Winter D, et al. Modern triage in the emergency department. Dtsch Arztebl Int. 2010 Dec; 107(50): 892-8. PMid: 21246025.

[12] Fernandes CMB, Tanabe P, Gilboy N, et al. Five-level triage: A report from the ACEP/ENA five-level triage task force. Journal of Emergency Nursing. 2005; 31(1): 39-50. PMid: 15682128. http://dx.doi.org/10.1016/j.jen.2004.11.002

[13] Emergency Severity Index (ESI): A Triage Tool for Emergency Department: Implementation Handbook, 2012 Edition. Agency for Healthcare Research and Quality, Rockville, MD. 2011. Available from: http://www.ahrq.gov/professionals/systems /hospital/esi/esi1.html

[14] Moll HA. Challenges in the validation of triage systems at emergency departments. J Clin Epidemiol. 2010; 63(4): 384-8. PMid: 19875271 http://dx.doi.org/10.1016/j.jclinepi.2009.07.009

[15] Platts-Mills, Timothy F, Debbie Travers, et al. Accuracy of the Emergency Severity Index Triage Instrument for Identifying Elder Emergency Department Patients Receiving an Immediate Life-saving Intervention. Academic Emergency Medicine. 2010; 17(3): 238-243.
PMid: 20370755. http://dx.doi.org/10.1111/j.1553-2712. $2010.00670 . \mathrm{x}$

[16] Travers DA, Waller AE, Katznelson J, et al. Reliability and Validity of the Emergency Severity Index for Pediatric Triage. Acad Emerg Med. 2009; 16(9): 843-9. PMid: 19845551. http://dx.doi.org /10.1111/j.1553-2712.2009.00494.x

[17] Van der Wulp I, Schrijvers AJ, van Stel HF. Predicting admission and mortality with the Emergency Severity Index and the Manchester Triage System: a retrospective observational study. Emergency medicine journal. 2009; 26(7): 506-9. PMid: 19546272 http://dx.doi.org/10.1136/emj.2008.063768

[18] Tanabe P, Gimbel R, Yarnold PR, et al. Reliability and validity of scores on The Emergency Severity Index version 3. Acad Emerg Med. 2004; 11(1): 59-65. PMid: 14709429. http://dx.doi.org /10.1197/j.aem.2003.06.013

[19] Mirhaghi A, Heydari A, Mazlom R, et al. Reliability of the Emergency Severity Index: Meta-analysis. Sultan Qaboos Univ Med J. 2015; 15(1): e71-7. PMid: 25685389.

[20] Bergs J, Verelst S, Gillet JB, et al. Evaluating Implementation of the Emergency Severity Index in a Belgian Hospital. Journal of emergency nursing official publication of the Emergency Department Nurses Association. 2014.

[21] Storm-Versloot MN, Ubbink DT, Chin a Choi V, et al. Observer agreement of the Manchester Triage System and the Emergency Severity Index: a simulation study. Emerg Med J. 2009; 26(8): 556-60. PMid: 19625548. http://dx.doi.org/10.1136/emj. 2008.059378

[22] Farrohknia N, Castrén M, Ehrenberg A, et al. Emergency department triage scales and their components: a systematic review of the scientific evidence. Scand J Trauma Resusc Emerg Med. 2011 Jun 30; 19: 42. PMid: 21718476. http://dx.doi.org/10.1186/1757-724 1-19-42

[23] Parenti N, Reggiani ML, Iannone P, et al. A systematic review on the validity and reliability of an emergency department triage scale, the Manchester Triage System. Int J Nurs Stud. 2014; 51(7): 10629. PMid: 24613653. http://dx.doi.org/10.1016/j.ijnurst u. 2014.01 .013

[24] Mirhaghi A, Kooshiar H, Esmaeili H, et al. Outcomes for emergency severity index triage implementation in the emergency department. $\mathbf{J}$ Clin Diagn Res. 2015; 9(4): OC04-7. http://dx.doi.org/10.78 $60 / j c d r / 2015 / 11791.5737$

[25] Eitel DR, Travers DA, Rosenau AM, et al. The emergency severity index triage algorithm version 2 is reliable and valid. Acad Emerg Med. 2003 Oct; 10(10): 1070-80. PMid: 14525740. http: //dx.doi.org/10.1111/j.1553-2712.2003.tb00577.x

[26] Azeredo TR, Guedes HM, Rebelo de Almeida RA, et al. Efficacy of the Manchester Triage System: a systematic review. Int Emerg Nurs. 2015; 23(2): 47-52. PMid: 25087059. http://dx.doi.org /10.1016/j.ienj.2014.06.001

[27] Weber EJ, McAlpine I, Grimes B. Mandatory triage does not identify high-acuity patients within recommended time frames. Ann Emerg Med. 2011; 58(2): 137-42. PMid: 21514968. http://dx.doi.org /10.1016/j.annemergmed.2011.02.001

[28] Grossmann FF, Zumbrunn T, Frauchiger A, et al. At Risk of Undertriage? Testing the Performance and Accuracy of the Emergency Severity Index in Older Emergency Department Patients. Ann Emerg Med. 2012; 60(3): 317-25. PMid: 22401951. http: //dx.doi.org/10.1016/j.annemergmed.2011.12.013

[29] Singer RF, Infante AA, Oppenheimer CC, et al. The Use of and Satisfaction with the Emergency Severity Index. Journal of Emergency Nursing. 2012; 38(2): 120-6. PMid: 22401616. http://dx.doi.o $\mathrm{rg} / 10.1016 / \mathrm{j} \cdot \mathrm{jen} \cdot 2010.07 .004$ 
[30] Garbez RO, Carrieri-Kohlman V, Stotts N, et al. Level 2 and level 3 patients in emergency severity index triage system: comparison of characteristics and resource utilization. Advanced emergency nursing journal. 2011; 33(4): 322-35. PMid: 22075683. http://dx.doi.org/10.1186/1472-6963-10-162

[31] Considine J, Botti M, Thomas S. Do knowledge and experience have specific roles in triage decision-making? Acad Emerg Med. 2007; 14(8): 722-6. PMid: 17656608. http://dx.doi.org/10.1111/j .1553-2712.2007.tb01869.x

[32] Dateo J. What factors increase the accuracy and inter-rater reliability of the Emergency Severity Index among emergency nurses in triaging adult patients? Journal of emergency nursing: JEN : official publication of the Emergency Department Nurses Association. 2013;
39(2): 203-7. PMid: 22079643. http://dx.doi.org/10.1016/j .jen.2011.09.002

[33] McHugh ML. Interrater reliability: the kappa statistic. Biochem Med (Zagreb). 2012; 22(3): 276-82. http://dx.doi.org/10.11613/ BM. 2012.031

[34] Hallgren KA. Computing Inter-Rater Reliability for Observational Data: An Overview and Tutorial. Tutor Quant Methods Psychol. 2012; 8(1): 23-34. PMid: 22833776.

[35] Steiner D, Renetseder F, Kutz A, et al. Performance of the Manchester Triage System in Adult Medical Emergency Patients: A Prospective Cohort Study. J Emerg Med. 2015. PMid: 26458788. http://dx.doi.org/10.1016/j.jemermed.2015.09.008 